\title{
High myopia and macular vascular density: an optical coherence tomography angiography study
}

Yang Jiang ${ }^{1,2}$, Shang Lou ${ }^{3}$, Ying $\mathrm{Li}^{1,2^{*}}$, Youxin Chen ${ }^{1,2}$ and Thomas Chengxuan Lu ${ }^{4}$

\begin{abstract}
Objective: To investigate whether there are differences inmacular vascular density (VD) between patients with highmyopia (HM) and those with non-high myopia (NHM) using Optical Coherence Tomography Angiography (OCTA).

Method: OCTA was performed on 35 eyes with HM with spherical equivalence (SE) > $-6.00 \mathrm{D}$ and 35 eyes with NHM with $\mathrm{SE} \leq-6.00 \mathrm{D}$. Vascular densities of the macula (overall macula, fovea, parafovea, superior hemi and inferior hemi) were measured in each of the superficial, deep and choriocapillaris layers of the retina.

Results: In the superficial retinal layer, overall macular VFD was significantly higher in the NHM compared to the HM group (51.27 \pm 3.74 vs. $48.07 \pm 5.69, p<0.05)$. There were significant differences between the NHM and HM in parafovea (52.58 \pm 5.78 vs. $49.4 \pm 6.43, p<0.05)$, superior-hemi $(53.38 \pm 4.03$ vs $49.78 \pm 6.84, p<0.05)$ and inferior-hemi regions $(53.49 \pm 4.61$ vs $49.05 \pm 6.41, p<0.05)$, but not in the fovea region. Similarly, in the deep retinal layer, overall macular VFD was significantly higher in the NHM group compared to the HM group (58.69 \pm 2.46 vs. $56.90 \pm 4.08$, $p<0.05)$. There was significant differences between the HM and NHM in superior-hemi region (61.97 $\pm 2.68 \mathrm{vs}$. $60.08 \pm 3.98, p<0.05)$, but not in the fovea, parafovea, and inferior-hemi region. In the choriocapillaris, there was no difference in the overall macular VFD, nor any of the individual sectors between the HM and the NHM groups.
\end{abstract}

Conclusion: VFD in the superficial and deep retinal layers of the macula are significantly increased in the NHM compared to HM eyes. This is not the case in the choroidal capillary layers of the retina.

\section{Background}

Uncorrected refractive error is common, affecting approximately 108 million people worldwide. It is also the second leading cause of blindness worldwide [1]. In a Japanese population study, $12.2 \%$ of vision impairment was caused by myopic macular degeneration [2]. Among other population-based studies, the prevalence of high myopia (HM) has been estimated to comprise 5 to $10 \%$ of diagnosed myopias, and 1 to $4 \%$ of the general population $[3,4]$. In the US population, it is estimated that HM has

\footnotetext{
*Correspondence: liyingpumch@126.com

${ }^{1}$ Department of Ophthalmology, Peking Union Medical College Hospital, Chinese Academy of Medical Sciences, Beijing 100730, China

Full list of author information is available at the end of the article
}

increased 8-fold over 30 years, from 0.2 to $1.6 \%$ [5]. Myopia therefore poses a significant social economic burden on both developing and developed countries.

High myopia is significantly associated with morphological changes within the retina [6-8]. It increases the risk of pathologic myopia leading to retinal atrophy, lattice degeneration, lacquer cracks, choroidal neovascularization, and retinal detachment [9]. In Japan, myopic maculopathy was reported to be the primary cause of legal blindness and the third most prevalent cause of poor vision [10]. In Western populations, myopic maculopathy is also a significant cause of legal blindness [11].

OCTA is a technique that measure light reflectance of moving red cells to visualize the retinal vasculature and microcirculation. It is quick, non-invasive and provides original author(s) and the source, provide a link to the Creative Commons licence, and indicate if changes were made. The images or other third party material in this article are included in the article's Creative Commons licence, unless indicated otherwise in a credit line to the material. If material is not included in the article's Creative Commons licence and your intended use is not permitted by statutory regulation or exceeds the permitted use, you will need to obtain permission directly from the copyright holder. To view a copy of this licence, visit http://creativecommons.org/licenses/by/4.0/. The Creative Commons Public Domain Dedication waiver (http://creativeco mmons.org/publicdomain/zero/1.0/) applies to the data made available in this article, unless otherwise stated in a credit line to the data. 
quantitative, blood flow and structural information [12]. We attempted to utilize OCTA to investigate differences in macular vascular density in non-pathologic HM compared to non-high myopia (NHM) patients. It is hypothesized that with increasing myopia, there is lower vascular density within the macula, reducing perfusion and predisposing to pathologic myopia. Establishing differences in patients without evidence of eye disease is important aspect to understanding the natural history and etiology of pathologic myopia.

\section{Methods}

\section{Participants}

This is a prospective, cross-sectional study. Seventy eyes with myopia were recruited consecutively over the period of December 2014 to December 2020 in the Department of Ophthalmology in Peking Union Medical College Hospital, Chinese Academy of Medical Sciences. Thirty-five eyes with HM and 35 eyes with NHM were recruited. $\mathrm{HM}$ was defined as a spherical equivalence (SE) less than $-6.00 \mathrm{D}$, and NHM defined as a SE greater than or equal to $-6.00 \mathrm{D}$. Only the OCTA index of the right eyes of the participants were recorded. Exclusion criteria included any history of other any ocular diseases, systemic diseases that may affect the ocular circulation and previous intraocular surgery or ocular injury. Case files and OCTA images were reviewed and discussed by two expert ophthalmologists. Exclusion was based on mutual agreement. This study had ethical approval from the institutional ethics committee of the Chinese Academy of Medical Sciences, Peking Union Medical College Hospital, and all data collection were performed in accordance with relevant regulations and guidelines.

\section{Optical coherence tomography angiography}

OCTA scans were obtained using OCT (Optovue, Fremont, California, USA) Angio-Retina mode $(3 \times 3 \mathrm{~mm})$. Split-spectrum amplitude decorrelation angiography (SSADA) was utilized as the signal process algorithm. This has been described in detail in previous literature. Vascular density (VD) is the percentage of the sample area occupied by vessel lumens. OCTA images excluded from this study include those with poor signal strength $(<40)$, images with severe artefacts, images which demonstrates epiretinal membrane, foveoschisis, macular holes, choroidal neovascularization and retinal detachments. A $3 \times 3 \mathrm{~mm}$ scanning area of the macula was acquired and divided into the superficial, deep and choroidal layers. Each of the layers were automatically segmented by the software. Results were analyzed with the Optovue software. VD of the overall macula was calculated, and each region was calculated separately (fovea, parafovea, superior-hemi and inferior-hemi).
Table 1 Demographic and Corneal Baseline Data

\begin{tabular}{llll}
\hline & NHM & HM & $\boldsymbol{p}$ \\
\hline Age (mean) & 27.3 & 25.6 & 0.811 \\
Male & 17 & 15 & 0.181 \\
Female & 18 & 20 & \\
SE (Diopters) & -3.46 & -7.57 & $<0.01$ \\
K1 (D) & $43.45 \pm 16.8$ & $44.07 \pm 14.2$ & 0.090 \\
K2 (D) & $42.53 \pm 14.9$ & $42.71 \pm 13.0$ & 0.614 \\
KMean (D) & $42.91 \pm 15.0$ & $43.44 \pm 12.9$ & 0.117 \\
CCT & $536.94 \pm 33.96$ & $543.82 \pm 33.32$ & 0.458 \\
\hline
\end{tabular}

SE Spherical Equivalence, KMean K mean, CCT central corneal thickness

Table 2 Macular Vascular Density in Superficial Retinal Layer of $\mathrm{NHM}$ and HM patients

\begin{tabular}{llll}
\hline & NHM $\left(\mathbf{m m}^{\mathbf{2}} \pm \mathbf{S D}\right)$ & $\mathbf{H M}\left(\mathbf{m m}^{\mathbf{2}} \pm \mathbf{S D}\right)$ & $\boldsymbol{p}$ \\
\hline Overall & $51.27 \pm 3.74$ & $48.07 \pm 5.69$ & 0.017 \\
Fovea & $28.75 \pm 5.22$ & $28.56 \pm 6.55$ & 0.890 \\
Parafovea & $52.58 \pm 5.78$ & $49.40 \pm 6.43$ & 0.043 \\
Superior-Hemi Region & $53.38 \pm 4.03$ & $49.78 \pm 6.84$ & 0.019 \\
Inferior-Hemi Region & $53.49 \pm 4.61$ & $49.05 \pm 6.41$ & 0.005 \\
\hline
\end{tabular}

\section{Statistical analysis}

SPSS software package (SPSS 12.0) was utilized to perform statistical analysis. The mean and standard deviation of the main parameters were calculated. The VD were compared between the two groups. A $p$-value calculated using the T-test, and a level of $<0.05$ was considered statistically significant.

\section{Results}

\section{Demographics}

Seventy right eyes (32 men and 38 women) were included in this study. The NHM group $(n=35)$ contained 18 women and 17 men with a mean age of $27.3 \pm 4.5$ years. The HM group $(n=35)$ contained 20 women and 15 men with a mean age of $25.6 \pm 5.4$ years. There were no significant differences in gender, age, K1, K2, Avek and CCT between the two groups (Table 1). Forty-one patients were excluded from the study.

\section{Macular density}

The superficial retinal layer showed an overall decrease in VFD in the HM group (Table 2). The overall macular VD were $51.27 \pm 3.74$ and $48.07 \pm 5.69$ in the NHM and HM groups, respectively $(p<0.05)$. The multiple sectorial comparisons showed that there were significant reductions in the VFD in the HM group in the parafovea $(52.58 \pm 5.78$ vs $49.40 \pm 6.43, p<0.05)$, superior-hemi $(53.38 \pm 4.03$ vs $49.78 \pm 6.84, p<0.05)$ and inferior-hemi 
Table 3 Macular Vascular Density in the Deep Retinal Layer of NHM and HM patients

\begin{tabular}{llll}
\hline & $\mathbf{N H M}\left(\mathbf{m m}^{\mathbf{2}} \pm \mathbf{S D}\right)$ & $\mathbf{H M}\left(\mathbf{m m}^{\mathbf{2}} \pm \mathbf{S D}\right)$ & $\boldsymbol{p}$ \\
\hline Overall & $58.69 \pm 2.46$ & $56.90 \pm 4.08$ & 0.041 \\
Fovea & $25.24 \pm 6.04$ & $24.98 \pm 6.97$ & 0.872 \\
Parafovea & $62.44 \pm 2.30$ & $61.10 \pm 3.55$ & 0.074 \\
Superior-Hemi Region & $61.97 \pm 2.68$ & $60.08 \pm 3.98$ & 0.029 \\
Inferior-Hemi Region & $62.90 \pm 2.43$ & $62.11 \pm 3.50$ & 0.270 \\
\hline
\end{tabular}

Table 4 Macular Vascular Density in the Choriocapillaris of NHM and HM Patients

\begin{tabular}{llll}
\hline & $\mathbf{N H M}\left(\mathbf{m m}^{\mathbf{2}} \pm \mathbf{S D}\right)$ & $\mathbf{H M}\left(\mathbf{m m}^{\mathbf{2}} \pm \mathbf{S D}\right)$ & $\boldsymbol{p}$ \\
\hline Overall & $65.50 \pm 1.62$ & $64.69 \pm 2.29$ & 0.137 \\
Fovea & $65.11 \pm 3.12$ & $63.48 \pm 5.48$ & 0.138 \\
Parafovea & $65.39 \pm 1.65$ & $64.56 \pm 2.22$ & 0.119 \\
Superior-Hemi Region & $65.31 \pm 1.65$ & $64.24 \pm 3.15$ & 0.108 \\
Inferior-Hemi Region & $65.49 \pm 1.76$ & $64.86 \pm 2.57$ & 0.284 \\
\hline
\end{tabular}

regions ( $53.49 \pm 4.61$ vs $49.05 \pm 6.41, p<0.05)$, but not in the fovea region $(28.75 \pm 5.22$ vs $28.56 \pm 6.55, p>0.05)$.

The deep retinal layer showed also an overall decrease in macular VFD in the HM group (Table 3). The overall macular VFD were $58.69 \pm 2.46$ and $56.90 \pm 4.08$ in the NHM and the HM groups, respectively $(p<0.05)$. In the individual sectorial comparisons, only the superiorhemi region showed a reduction in VFD in the HM group $(61.97 \pm 2.68$ vs $60.08 \pm 3.98, p<0.05)$. There were no significant differences in the in the fovea $(25.24 \pm 6.04$ vs $24.98 \pm 6.97)$, parafovea $(62.44 \pm 2.30$ vs $61.10 \pm 3.55)$ and inferior-hemi region $(62.90 \pm 2.43$ vs $62.11 \pm 3.50)$ $(p>0.05)$ (Table 3).

The choriocapillaris showed no significant differences in the HM and NHM groups overall and in each of the individual sectors (Table 4). The overall macular VFD were $65.50 \pm 1.62$ and $64.69 \pm 2.29$ in the HM and NHM groups respectively $(p>0.05)$. There was no significant differences between the HM and NHM patients in the fovea $(65.11 \pm 3.12$ vs $63.48 \pm 5.48)$, parafovea $(65.39 \pm 1.65$ vs $64.56 \pm 2.22)$, superior-hemi region $(65.31 \pm 1.65$ vs $64.24 \pm 3.15)$ and inferior-hemi region $(65.49 \pm 1.76$ vs $64.86 \pm 2.57)(p>0.05)$.

\section{Discussion}

High myopia is well-known to be associated with significant histopathological changes of the retina [7] and can lead to myopic maculopathy. Various degenerative changes can become evident in the posterior segment. In many developed countries, myopic maculopathy remains one of the key causes of visual impairment [13].

Although the etiology of myopic maculopathy is still elusive, previous literature has suggested that increased radius of the eyeball in HM eyes lead to reduced blood circulation [14-16]. There is evidence that reduced choroidal blood flow over a prolonged period of time leads to release of vascular endothelial growth factor (VEGF) and consequent myopic choroidal neovascularization (CNV) [17]. Myopic CNV was shown to have a prevalence rate of $10-11 \%$ over the period of 12 years in one study [18]. The pathogenesis of myopic maculopathy may stem from a similar pathophysiological pathway.

Previous studies of retinal vasculature in HM eyes have focused on the use of time domain OCTs (TD-OCT) and Colour Doppler Imaging (CDIs). Axial length has been correlated with regional variations of retinal thickness [19] and negatively correlated with choroidal or retinal blood flow. Such studies have had difficulty visualizing the microvasculature, and experienced poor differentiation of static tissue to vasculature. Other techniques which have being utilized to investigate retinal blood flow include fluorescein angiography (FA). The utility of FA in $\mathrm{HM}$ is low due to its invasive and qualitative nature. Any potential side effects are further avoided in OCTA.

OCTA allows detailed, three-dimensional study of vasculature down to the capillary level. It utilizes the intrinsic motion of blood cells present in the vascular networks, offering a non-invasive and rapid test without the need for intravenous contrast [20].

In our study, OCTA was utilized to compare the macular VD of patients with NHM and HM without pathologic myopia. The SE of $-6.00 \mathrm{D}$ was utilized to differentiate between the two groups. Our study demonstrates that HM is associated with a reduced macular VD. This finding supports the hypothesis that reduced macula perfusion leads to pathologic myopia. Further studies are required to explore the exact pathophysiological mechanism for mean decrease in macula vascular density.

Multiple studies have demonstrated decreasing macular VD being associated with increasing myopia [21, 22]. Some studies have demonstrated only differences in certain regions and layers [23, 24], whilst others have not demonstrated any differences between high myopic and non-high myopic patients [25-27]. This difference in the literature could be attributable to selection of population. Studies which demonstrated non-significant difference between VD of myopic and high-myopic patients had relatively narrow age ranges of patients [25]. Although the pathogenesis of myopic maculopathy is still relatively unknown, prognosis of patients with myopic maculopathy worsens with age [28]. With increasing age, a greater reduction of macular VD occurs. In sample sizes with 
younger patients, changes in VD may not be reflected. Future studies are needed with larger data-sets, with greater time-frames to allow for accurate complex multivariable analysis. A systematic synopsis of the current published studies would be highly important.

Limitations to our study includes the lack of regression analysis to examine for other factors such as axial length which could contribute to the reported differences in macula vascular density. Although there has not been formal power analysis undertaken, our study is of similar size to previous published investigations [24].

In conclusion, our study has demonstrated negative correlations between high myopia and both the superficial and deep retinal vascular flow density readings as attained by OCTA.

\section{Acknowledgements}

Not applicable.

\section{Authors' contributions}

All authors had input into the conception of the study. YJ undertook data extraction. YJ and TCL wrote and revised the main manuscript text. All authors reviewed the manuscript and approved it for publication.

\section{Funding}

This work was supported by The Non-profit Central Research Institute Fund of Chinese Academy of Medical Sciences (2018PT32029).

\section{Availability of data and materials}

Data supporting the results reported in the article are not public but can be accessed after communicating with the corresponding author.

\section{Declarations}

\section{Ethics approval and consent to participate}

All patients gave their informed consent for their anonymized data to be submitted for audit and publication. The institutional ethics committee of Chinese Academy of Medical Sciences, Peking Union Medical College Hospital approved this study. All methods were carried in line with ethics approval.

\section{Consent for publication}

Not applicable.

\section{Competing interests}

The authors declare that they have no competing interest.

\section{Author details}

'Department of Ophthalmology, Peking Union Medical College Hospital, Chinese Academy of Medical Sciences, Beijing 100730, China. ${ }^{2}$ Key Laboratory of Ocular Fundus Diseases, Chinese Academy of Medical Sciences \& Peking Union Medical College, Beijing, China. ${ }^{3}$ Department of Ophthalmology, Jiangxi Cancer Hospital, Nanchang Beijing ease road No.519, Jiang xi, China. ${ }^{4}$ School of Medicine, University of New South Wales, Kensington, NSW 2052, Australia.

Received: 27 May 2021 Accepted: 4 October 2021

Published online: 27 November 2021

\section{References}

1. He M, Huang W, Zheng Y, Huang L, Ellwein LB. Refractive error and visual impairment in school children in rural southern China. Ophthalmology. 2007;114(2):374-82

2. Yamada M, Hiratsuka Y, Roberts CB, Pezzullo ML, Yates K, Takano S, et al. Prevalence of visual impairment in the adult Japanese population by cause and severity and future projections. Ophthalmic Epidemiol. 2010;17(1):50-7.

3. Wong TY, Ferreira A, Hughes R, Carter G, Mitchell P. Epidemiology and disease burden of pathologic myopia and myopic choroidal neovascularization: an evidence-based systematic review. Am J Ophthalmol. 2014;157(1):9-25 e12

4. Vongphanit J, Mitchell P, Wang JJ. Prevalence and progression of myopic retinopathy in an older population. Ophthalmology. 2002;109(4):704-11.

5. Vitale S, Sperduto RD, Ferris FL 3rd. Increased prevalence of myopia in the United States between 1971-1972 and 1999-2004. Arch Ophthalmol. 2009;127(12):1632-9.

6. Avetisov ES, Savitskaya NF. Some features of ocular microcirculation in myopia. Ann Ophthalmol. 1977;9(10):1261-4.

7. Jonas JB, Xu L. Histological changes of high axial myopia. Eye (Lond). 2014;28(2):113-7.

8. Xu L, Li Y, Wang S, Wang Y, Wang Y, Jonas JB. Characteristics of highly myopic eyes: the Beijing eye study. Ophthalmology. 2007;114(1):121-6.

9. Morgan IG, Ohno-Matsui K, Saw SM. Myopia. Lancet. 2012;379(9827):1739-48.

10. Liu HH, Xu L, Wang YX, Wang S, You QS, Jonas JB. Prevalence and progression of myopic retinopathy in Chinese adults: the Beijing eye study. Ophthalmology. 2010;117(9):1763-8.

11. Buch H, Vinding T, La Cour M, Appleyard M, Jensen GB, Nielsen NV. Prevalence and causes of visual impairment and blindness among 9980 Scandinavian adults: the Copenhagen City eye study. Ophthalmology. 2004;111(1):53-61.

12. de Carlo TE, Romano A, Waheed NK, Duker JS. A review of optical coherence tomography angiography (OCTA). Int J Retina Vitreous. 2015;1:5.

13. Resnikoff S, Pascolini D, Mariotti SP, Pokharel GP. Global magnitude of visual impairment caused by uncorrected refractive errors in 2004. Bull World Health Organ. 2008:86(1):63-70.

14. Akyol N, Kukner AS, Ozdemir T, Esmerligil S. Choroidal and retinal blood flow changes in degenerative myopia. Can J Ophthalmol. 1996;31(3):113-9.

15. Moriyama M, Ohno-Matsui K, Futagami S, Yoshida T, Hayashi K, Shimada $\mathrm{N}$, et al. Morphology and long-term changes of choroidal vascular structure in highly myopic eyes with and without posterior staphyloma. Ophthalmology. 2007;114(9):1755-62.

16. Wakabayashi T, Ikuno Y. Choroidal filling delay in choroidal neovascularisation due to pathological myopia. Br J Ophthalmol. 2010;94(5):611-5.

17. Silva R. Myopic maculopathy: a review. Ophthalmologica. 2012:228(4):197-213.

18. Hayashi K, Ohno-Matsui K, Shimada N, Moriyama M, Kojima A, Hayashi W, et al. Long-term pattern of progression of myopic maculopathy: a natural history study. Ophthalmology. 2010;117(8):1595-611 1611 e1591-1594.

19. Lam DS, Leung KS, Mohamed S, Chan WM, Palanivelu MS, Cheung CY, et al. Regional variations in the relationship between macular thickness measurements and myopia. Invest Ophthalmol Vis Sci. 2007;48(1):376-82.

20. Wang RK. Optical microangiography: a label free $3 \mathrm{D}$ imaging technology to visualize and quantify blood circulations within tissue beds in vivo. IEEE J Sel Top Quantum Electron. 2010;16(3):545-54.

21. Min CH, Al-Qattan HM, Lee JY, Kim JG, Yoon YH, Kim YJ. Macular microvasculature in high myopia without pathologic changes: an optical coherence tomography angiography study. Korean J Ophthalmol. 2020:34(2):106-12.

22. Cheng D, Chen $Q$, Wu Y, Yu X, Shen M, Zhuang X, et al. Deep perifoveal vessel density as an indicator of capillary loss in high myopia. Eye (Lond). 2019;33(12):1961-8

23. Hassan M, Sadiq MA, Halim MS, Afridi R, Soliman MK, Sarwar S, et al. Evaluation of macular and peripapillary vessel flow density in eyes with no known pathology using optical coherence tomography angiography. Int J Retina Vitreous. 2017:3:27.

24. Mo J, Duan A, Chan S, Wang X, Wei W. Vascular flow density in pathological myopia: an optical coherence tomography angiography study. BMJ Open. 2017;7(2):e013571.

25. Yang S, Zhou M, Lu B, Zhang P, Zhao J, Kang M, et al. Quantification of macular vascular density using optical coherence tomography angiography and its relationship with retinal thickness in myopic eyes of young adults. J Ophthalmol. 2017;2017:1397179.

26. Tan CS, Lim LW, Chow VS, Chay IW, Tan S, Cheong KX, et al. Optical Coherence Tomography Angiography Evaluation of the Parafoveal Vasculature 
and Its Relationship With Ocular Factors. Invest Ophthalmol Vis Sci. 2016;57(9):Oct224-34.

27. Yu J, Jiang C, Wang X, Zhu L, Gu R, Xu H, et al. Macular perfusion in healthy Chinese: an optical coherence tomography angiogram study. Invest Ophthalmol Vis Sci. 2015;56(5):3212-7.

28. Shih YF, Ho TC, Hsiao CK, Lin LLK. Visual outcomes for high myopic patients with or without myopic maculopathy: a 10 year follow up study. Br J Ophthalmol. 2006;90(5):546-50.

\section{Publisher's Note}

Springer Nature remains neutral with regard to jurisdictional claims in published maps and institutional affiliations.

- fast, convenient online submission

- thorough peer review by experienced researchers in your field

- rapid publication on acceptance

- support for research data, including large and complex data types

- gold Open Access which fosters wider collaboration and increased citations

- maximum visibility for your research: over $100 \mathrm{M}$ website views per year

At BMC, research is always in progress.

Learn more biomedcentral.com/submissions 